\title{
Jerusalén en la obra de Amos Oz
}

\author{
Raquel SÁNCHEZ GARCÍA \\ Universidad Complutense de Madrid \\ raquel.snchez@gmail.es
}

Recibido: 1 de abril de 2011

Aceptado: 22 de abril de 2011

\section{Resumen}

Jerusalén se halla muy presente en la obra de Amos Oz. Su retrato de la ciudad está basado en la memoria, en la familia y en la infancia. Lejos de reiterar los tópicos acerca de la ciudad mítica, de la ciudad sagrada, Oz ofrece los perfiles de la Jerusalén de la gente corriente, del judío atrapado en su trauma histórico. La Jerusalén de Oz es la contraparte de las activas Haifa y Tel Aviv, y de las sofisticadas ciudades europeas de las que procedían los refugiados que compartieron las calles de su barrio en los años cuarenta del siglo XX. El objetivo de este artículo es realizar una lectura de esta ciudad a través de la obra de Amos Oz.

Palabras clave: Jerusalén, mandato británico, Segunda Guerra Mundial, literatura israelí, Israel.

Title: Jerusalem in the work of Amos Oz

\section{Abstract}

The city of Jerusalem is very important in Amos Oz's work. His portrait of the city is based on memory, family and childhood. Far from reiterating the topics of the mythical and the holy city, Oz offers a picture of the Jerusalem of the ordinary people, the people caught in the Jewish historical trauma. Oz's Jerusalem is the counterpart of the active Haifa and Tel Aviv and of the sophisticated European cities from came the refugees who shared the streets of Oz's neighbourhood in the forties of the twentieth century.

Keywords: Jerusalem, British mandate, Second World War, Israeli literature, Israel.

\section{Índice}

1. Un barrio lejos de la ciudad mítica

2. La casa: refugio y cárcel

3. El otro en la ciudad

4. La ciudad fragmentada

5. Conclusión 
Jerusalén, uno de los mitos religiosos del mundo occidental; Jerusalén, el mito político del estado de Israel. Entre ambas dimensiones, mito religioso / mito político, camina una de las ciudades clave para entender la historia de nuestro entorno desde la Edad Media (Berriot-Salvadore 1995). Las aproximaciones a la ciudad han sido muchas. Los cruzados, los viajeros, los iluminados, marcharon hacia ella considerándola el destino final del viaje a Tierra Santa. La tierra más deseada, capital de Judea, la tierra de promisión y redención se convirtió así en una ciudad mítica, en la que el conflicto bélico ha sido siempre el símbolo del propio conflicto del hombre consigo mismo, un espejo de la lucha del ser humano contra el mal que porta en su interior. Por otra parte, con el despertar del sionismo, Jerusalén ofrece otra faceta de su carácter mítico y se transforma en potencial capital de un estado propiamente judío. EI mito político se fue configurando en las décadas finales del siglo XIX y en los inicios del siglo XX como referencia ineludible de todo proyecto estatal judío en Palestina ${ }^{1}$. Sin embargo, y aunque resulte una afirmación obvia, Jerusalén es una ciudad, una ciudad en la que han vivido, viven y vivirán personas. A partir de ahí, las preguntas se multiplican: ¿cómo contemplar la ciudad desde dentro?, ¿cómo explicar el devenir cotidiano en ese espacio?, ¿cómo se vive en una ciudad mítica?

Amos $\mathrm{Oz}$, uno de los escritores israelíes más reconocidos en la actualidad, nos ofrece una visión de esa Jerusalén que carga con su carácter mítico y lo hace descansar sobre la vida de sus habitantes de forma aplastante. Jerusalén es un personaje más en la obra de Oz: la ciudad es el marco de una buena parte de sus historias, pero también es el elemento condicionante del carácter de los jerosolimitanos. Jerusalén es el reverso de otras ciudades israelíes, europeas, norteamericanas. Jerusalén representa también la condensación del espíritu judío, con su pasado remoto, con su pasado reciente; un espíritu que ahoga a los personajes de $\mathrm{Oz}$, ansiosos de aire fresco lejos de la ciudad agobiante. Por otra parte, Jerusalén es, en la obra de Oz, la ciudad de la infancia, de su infancia. La ciudad de la familia que él abandonará a los quince años buscando la libertad en el kibutz Hulda, en el centro de Israel. Tal vez la obra en la que retrata de forma más significativa la ciudad sea Una noche de amor y oscuridad, publicada en hebreo en el año 2002, en la que el autor recuerda la trayectoria de su familia y la suya propia. Aquí se harán muchas referencias a esta novela pues es en ella donde Jerusalén aparece más claramente como el reverso del mito, del mito religioso y del mito político. Sin embargo, dado el hecho de la casi omnipresencia de

\footnotetext{
${ }^{1}$ Puede atribuirse a Moses Hess la moderna idea política de Jerusalén como capital de un estado judío en su obra Rom und Jerusalem, die Letze Nationalitätfrage (Leipzig, 1862).
} 
la ciudad en la literatura de $\mathrm{Oz}$, se mencionarán otras obras en las que Jerusalén alcanza un gran protagonismo, como Mi querido Mijael, con la que, según el propio $\mathrm{Oz}$, quiso dar la espalda definitivamente $a$ la ciudad (Oz 2008a: 437).

La Jerusalén de Amos Oz se sitúa cronológicamente entre los años cuarenta y la actualidad, pero sobre todo entre los cuarenta y los cincuenta del siglo XX. Durante esa época, la ciudad vivió una situación especial. Jerusalén formaba parte del Imperio Otomano. Después de la derrota otomana en la Primera Guerra Mundial, la Sociedad de Naciones encargó al Reino Unido vigilar el territorio a través de la figura jurídica del Mandato. A las crecientes hostilidades entre árabes y judíos, se unió la llegada creciente de judíos europeos que huían del antisemitismo. Tras la derrota nazi en 1945, los judíos, impacientes por la creación de un estado propio, recelaron de la actitud ambigua de los británicos, y los más radicales, el Irgún, grupo liderado por Menahem Begin, atacó el Hotel Rey David (que alojaba varios departamentos del Mandato). Este fue el inicio de una hostilidad creciente que perduró hasta la creación del estado de Israel el 14 de mayo de 1948. El Plan de Partición, votado en la ONU el 29 de noviembre de 1947, había establecido la creación de dos estados, uno judío y otro árabe, quedando Jerusalén como ciudad internacional, hasta que estalló la guerra unos meses después.

\section{Un barrio lejos de la ciudad mítica}

Esa infancia en Jerusalén se desarrolla en un barrio: Kerem Abraham, nacido a partir de un asentamiento de trabajadores judíos creado en 1853. Fue precisamente a mediados del siglo XIX cuando comenzaron a construirse en Jerusalén los primeros barrios exteriores a las murallas para acoger a los judíos de la diáspora. Kerem Abraham era un barrio pobre. En Una noche de amor y oscuridad, Kerem Abraham se opone continuamente a otros barrios de la ciudad como Talpiot y Rehavia. Kerem Abraham estaba habitado por

[...] sus vendedores ambulantes, sus tenderos, sus pequeños comercios y sus comerciantes hablando yiddish, con sus ultraortodoxos entonando cánticos sinagogales, su pequeña burguesía desplazada, sus excéntricos intelectuales revolucionarios [...]. En casa flotaba siempre el incierto sueño de ir a vivir a un barrio más civilizado. (Oz 2008a: 373)

Su barrio era, como dice el propio autor, un barrio chejoviano. Y frente a esto, Talpiot: "la versión jerosolimitana del barrio ajardinado berlinés, una especie de colina tranquila y boscosa entre cuyos árboles resplandecerían con los años los tejados de tejas rojas y en cuyas casas habitarían en paz y prosperidad intelectuales insignes, escritores famosos 0 investigadores reconocidos" (Oz 
2008a: 112). Estas zonas de Jerusalén son, como escribe el autor, "la ciudad" por la que pasaba de vez en cuando, a la que ir era un acontecimiento:

La Jerusalén que mis padres admiraban estaba lejos de nuestro barrio: estaba en la verde Rehavia llena de sonidos de piano, en los tres o cuatro cafés con lámparas doradas de la calle Yafo y Ben Yehuda, en las salas del YMCA y en el hotel Rey David, donde judíos y árabes amantes de la cultura se reunían con británicos amables e instruidos, por donde pululaban señoras fantásticas de largos cuellos vestidas de fiesta del brazo de señores con trajes claros, donde se mezclaban ingleses liberales con judíos cultos y árabes ilustrados, donde se organizaban recitales, bailes, jornadas literarias, recepciones, refinadas charlas artísticas. (Oz 2008a: 10)

El contraste de los mundos que representan estos barrios no se queda ahí, pues en su imaginación infantil existe otro paisaje que contraponer al reseco y triste Kerem Abraham: el mundo de los relatos. En su imaginario literario, construido a partir de historias narradas o contadas, el niño recrea un ambiente nunca visto por él: el de los espacios verdes, los grandes bosques y prados: "vagaba sin cesar, perdido, sonámbulo, por aquellos bosques virtuales, por aquellos bosques de palabras, prados de palabras" (Oz 2008a: 217). La misma recreación de ambientes que realiza el también niño Sumji, de La bicicleta de Sumji. Todo este mundo de ficción se contrapone a los tejados de uralita, los patios llenos de polvo, el calor. "Lo que me rodeaba no me interesaba", afirma el escritor. Se trata de un mundo que para él significa libertad y aire, frente a la asfixia de su entorno próximo. Esta imagen se manifiesta en el contraste entre Oriente, su mundo, y Occidente; contraste que también se encuentra en las apreciaciones de su abuela Shlomit acerca de Jerusalén como un lugar asiático $y$, por lo tanto, peligroso y sucio. De forma contradictoria, su familia paterna, profundamente sionista, mantenía el prejuicio de Jerusalén, y de Palestina por extensión, como un mundo oriental y asiático y, por lo tanto, amenazador. Amos Oz no tiene estas prevenciones occidentalistas con respecto a OrienteJerusalén, pero al narrar el calor y el polvo de las calles de Kerem Abraham, el lector percibe cómo este ambiente ahoga al niño, en un evidente símbolo del peso cultural e histórico del judaísmo que aplasta su crecimiento como persona. En otras novelas de $\mathrm{Oz}$, la ciudad ahoga, pero no por su calor, sino por la lluvia incesante que convierte en gris el mundo interno de los protagonistas, como sucede en Fima o en Mi querido Mijael. "Jerusalén es una ciudad que produce tristeza", dice Jana, la protagonista de Mi querido Mijael, "pero en cada momento y en cada estación la tristeza es diferente" (Oz 2007: 74). 
La sensación de vivir en un entorno pequeño, triste, pobre y angustioso se traslada a espacios más amplios, y así, lo que representa el barrio, también lo encarna la propia ciudad de Jerusalén frente al resto del mundo. Resulta significativo que a lo largo de Una noche de amor y oscuridad se insista reiteradamente en que, más allá de Jerusalén, existe "el verdadero mundo", "el gran mundo". Jerusalén es un lugar aislado, mientras que Tel Aviv permanece "unida-al-resto-del-mundo"; Tel-Aviv, la efervescente (Oz 2008b: 33). Ese otro mundo es el de la sofisticación y el cosmopolitismo, el de la cultura (y no la erudición), el del viaje. La naturaleza distinta de ambas ciudades determina el aspecto físico y la forma de moverse de sus habitantes. Tel Aviv es la tierra del nuevo judío, del judío libre de Israel; Jerusalén es la ciudad del judío derrotado: "En Tel-Aviv se caminaba de otra forma: se saltaba, se flotaba, como Neil Armstrong en la luna. En Jerusalén se caminaba siempre como en un entierro, o como cuando se llega tarde a un concierto" (Oz 2008a: 14-15). El mismo Oz, esta vez adoptando el papel de persona mayor que ya conoce lo que en su infancia no alcanzaba a ver, confiesa que, años después, se enteró de que aquella Jerusalén de su niñez tenía una gran vida cultural, a la que él, sus padres y sus vecinos permanecían ajenos. Sin embargo, lo interesante de todo eso gira alrededor de la idea de la existencia de un "mundo verdadero", en el que viven otros, en el que la existencia humana tiene un sentido más allá de las minucias cotidianas de las personas de su barrio chejoviano, gentes vencidas, con vidas inútiles atrapadas en el tedio de la rutina.

Otro elemento clave en esta comparación de espacios, barrios y ciudades, es la sombra que proyecta Europa sobre los lugares de aluvión de emigrantes. Se trata de una Europa de la que todos ellos proceden, cuyo recuerdo persiste en la forma de construir las casas, en las comidas, en los idiomas que se hablan, pero sobre todo se mantiene en la sensación de pérdida. Jerusalén representa la ciudad prometida, el mito religioso, pero los nuevos residentes, los recién llegados, no dejan de añorar la cultura europea, la civilización europea, sus ciudades de procedencia. Se produce un desajuste entre la certeza de no poder vivir en ningún otro lugar (a causa del antisemitismo), el desarraigo y la sensación de haber sido traicionados por sus vecinos y compatriotas europeos. Todo ello a la vez que se evocan continuamente los recuerdos del pasado; se evocan y se recrean, transformándolos. Esa es la situación de la propia familia del protagonista y de ahí viene una de las razones que convierte en insoportable para Oz su vida en la ciudad, ya que él, niño nacido en Jerusalén, no quiere sentir el peso de un pasado que no le pertenece. El recuerdo del pasado europeo conduce a vivir en un estado de comparación con la vida en Jerusalén, con la dureza de la existencia en esos nuevos barrios, lejos de Praga, donde estudió su madre, lejos de Vilna, donde vivió su padre. Sin embargo, esa 
connotación dual acerca de Europa adquiere perfiles positivos por todo lo que tiene de herencia cultural, de lugar donde existen esos literarios prados y bosques verdes de las ficciones que sirven al niño Oz para construir un mundo paralelo.

La proximidad de los grandes referentes religiosos del judaísmo no parece ser suficiente para llenar el vacío de muchos refugiados y, en particular, de las familias paterna y materna de nuestro autor. Hay que tener en cuenta que, a pesar de que Jerusalén es la ciudad santa para los judíos, la familia de $\mathrm{Oz}$, los Klausner y los Mussman, no eran fervientes creyentes del judaísmo, seguidores estrictos de los rituales, por lo que para ellos el significado religioso de la ciudad quedaba matizado por otros conceptos ${ }^{2}$. Es cierto que en su infancia Oz acudió a una escuela religiosa, el Tajkemoní, pero a causa de que la otra escuela que había en su barrio, el Colegio Berl Katznelson para los Hijos de los Trabajadores, tenía una clara ideología izquierdista de la que su padre abominaba. Eso no significa que la cuestión religiosa no aparezca en la obra de Amos Oz, pero lo que observamos es su peculiar forma de acercarse a la creencia, que no tiene ninguna vinculación con la ciudad de Jerusalén.

En efecto, en Una historia de amor y oscuridad la Jerusalén santa, la ciudad de las tres religiones está completamente ausente del libro. El niño $\mathrm{Oz}$ cuenta las impresiones que le producía el centro de la ciudad, la Ciudad Vieja, en las pocas ocasiones en que pasaba por allí:

[...] y penetramos en el mundo de los cipreses, las murallas, las rejas, las cornisas y los muros de piedra de una Jerusalén extraña, una Jerusalén que casi no conocía, la etíope, la árabe, la peregrina, la otomana, la misionera, la alemana, la griega, la astuta, la armenia, la americana, la monacal, la italiana, la rusa, la repleta de pinos, la temerosa y la cautivadora con sus campanas y sus encantamientos alados prohibidos para ti por ser un extraño, una ciudad velada, guardiana de peligrosos secretos, llena de cruces, torres, mezquitas y misterios, altanera y silenciosa; por sus calles vagaban como sombras oscuras sacerdotes de religiones extranjeras cubiertos con túnicas negras y sotanas negras, curas, monjas, cadíes, muecines, notables, devotos, peregrinos, velos de mujeres y capuchas de frailes. (Oz 2008a: 471)

Esta ciudad misteriosa es la Ciudad Vieja, la ciudad de las religiones, el punto de destino de tantos peregrinos y viajeros, ciudad ajena para $\mathrm{Oz}$ y para su familia, para quienes el mito político se sobreponía al mito religioso. En el niño Amos, los héroes de los textos

\footnotetext{
${ }^{2}$ El apellido original de Amos $\mathrm{Oz}$ es Klausner. Cuando decidió marcharse a vivir al kibutz Hulda, y con el deseo de olvidar su propio pasado, adoptó el apellido Oz, que significa fuerza y coraje.
} 
sagrados se convierten en héroes guerreros del pueblo de Israel, en elementos fundamentales de la época gloriosa, dentro de la creación del mito político judío que había aprendido en el seno de su propia familia (Balaban 1993: 12-13). De hecho, hay un momento, tras la guerra de los años 1947-1948, cuando los hebreos pierden la parte judía de la Ciudad Vieja, en que la familia Klausner, seguidora de Jabotinsky, acusa a Ben Gurión, primer ministro del estado de Israel, de haber abandonado el mito de Jerusalén, sobre todo por su significado político ${ }^{3}$.

\section{La casa: refugio y cárcel}

"Nací y crecí en un piso muy pequeño, de techos bajos y unos treinta metros cuadrados". Con esta declaración comienza la novela, con un inicio que reitera la sensación de opresión y ahogo que le produce la ciudad y su barrio en particular. En la Jerusalén de la época, el hacinamiento era la tónica habitual en una ciudad con una gran densidad de población y una continua llegada de refugiados. Para Oz, la sensación de ahogo de su casa y de la ciudad marca una fuerte impresión en los espíritus $y$, en este sentido, se plantea hasta qué punto todo ello pudo repercutir en el suicidio de su madre. Se trata, una vez más, del contraste con la vida en Europa, donde la familia de su madre disponía de una casa señorial en Rovno, y el espacio gris donde se desarrollaba su vida en Jerusalén ${ }^{4}$. Estas palabras nos aclaran sus percepciones:

Al cabo de algunos años, en el barrio de Kerem Abraham, en la calle Amós, en el semisótano asfixiante y húmedo, debajo de los Rosendorf y al lado de los Lemberg, entre barreños metálicos, pepinillos en vinagre y adelfas que se iban marchitando en latas oxidadas de aceitunas, rodeada todo el día por olores a repollo, colada, pescado cocinado y orines secos, mi madre empezó a consumirse. Tal vez fuera capaz de apretar los dientes y enfrentarse a una tragedia y a una pérdida. A la pobreza. Al desengaño de la vida matrimonial. Pero creo que de ningún modo pudo soportar el deterioro. (Oz 2008a: 323)

Las casas de Jerusalén, como metáfora de la limitación del espacio, ofrecen distintos perfiles. Por un lado, la pervivencia de la

\footnotetext{
${ }^{3}$ Zeev Jabotinsky fue un sionista de origen ruso, fundador de la Legión Judía que luchó en la Primera Guerra Mundial y que lideró el movimiento del sionismo revisionista. Se le considera el padre ideológico de la derecha israelí.

${ }^{4}$ La madre de $\mathrm{Oz}$ se suicidó cuando su hijo tenía entre once y doce años. Rovno (Ucrania), su lugar de procedencia, fue ocupada por las tropas nazis, las cuales, entre junio de 1941 y julio de 1942, acabaron con toda la población judía de la ciudad, hecho que impactó enormemente a Fania Mussman, la madre de Oz. La novela Mi querido Mijael responde a un intento de Amos Oz de comprender la muerte de su madre.
} 
huella europea, "como si quisieran aquí una copia de sus pueblos de Polonia, Ucrania, Hungría o Lituania" (Oz 2008a: 194). Por otro lado, responden a una construcción masiva, impersonal: "Uno tras otro se fueron construyendo edificios de piedra cuadrangulares, sencillos, de dos o tres plantas divididas en un montón de pisos agobiantes con las habitaciones diminutas" (Oz 2008a: 193). Y si el lector pasa del exterior al interior del semisótano de la familia Klausner, se encontrará con un espacio que se transforma por la noche para dejar lugar a las camas, en una habitación en la que por el día el sillón permitía el recibimiento de vecinos y familiares:

mis padres dormían en un sofá cama que ocupaba su habitación de pared a pared cuando lo abrían por las noches. Por la mañana temprano plegaban el sofá sobre si mismo, escondían la ropa de cama en la oscuridad del cajón de abajo, daban la vuelta al colchón, cerraban, empujaban, lo cubrían con una funda gris clara y unos cuantos cojines bordados de estilo oriental, ocultando cualquier rastro de sueño nocturno. Así pues, su habitación servía de dormitorio, estudio, biblioteca, comedor y salón. (Oz 2008a: 7)

Las casas no sólo tenían una dimensión privada, pues estos espacios limitados eran algo más que lugares para vivir: constituían el marco en el que se establecían las relaciones sociales de los habitantes. Las casas aparecen así como espacios fronterizos: públicos y privados. Se trataba de relaciones familiares, pero también de relaciones de amistad. La reunión de las personas en una casa, siguiendo la tradicional costumbre, servía como mecanismo de cohesión de los lazos familiares y de amistad, reforzaba el sentido de grupo y permitía el intercambio de noticias. No hay que olvidar que estamos ante personas que vivían en la ciudad desde hacía pocos años, para las que consolidar esas relaciones personales era fundamental en su intento de reconstruir la vida dejada en Europa y de reforzar su equilibrio psicológico después de los traumas causados por el antisemitismo. En este sentido, Amos Oz nos describe cómo se realizaba este ritual, cómo se hallaban marcadas unas pautas de comportamiento que se repetían independientemente del tamaño del entorno (es decir, de las dimensiones de la casa) y de las personas que allí estuvieran. Hombres y mujeres se distribuían en el espacio. Las mujeres de la casa hacían los ofrecimientos de café 0 , preferiblemente, de té, y los hombres conducían la discusión. En el caso de las familias paterna y materna de Oz se observa una clara impronta de las costumbres eslavas, lituana y ucraniana.

En el espacio privado, la casa, las lenguas eran un elemento que delimitaba espacios invisibles, mundos ajenos. Los espacios compartidos eran los del hebreo; los espacios íntimos o privados eran los de las lenguas de procedencia. En Una historia de amor y 
oscuridad, Oz narra cómo los idiomas constituían barreras que marcaban mundos distintos, no sólo en lo cultural, sino incluso en lo vital. Sus padres insistieron en que él fuera educado en hebreo, con lo que ello suponía pues, como se dice en la novela, "en aquella época había una gran carencia de palabras: el hebreo no era aún una lengua natural, y por supuesto no era una lengua íntima" (Oz 2008a: 21). Sin embargo, el hebreo era el idioma del futuro estado, la lengua del nuevo hombre judío en la Tierra Prometida, una lengua de renovación. Se trataba de un nuevo hebreo, producto del esfuerzo lingüístico de Eliézer Ben Yehuda, muy lejos del hebreo bíblico. Esa es la diferencia que observará Profi, el niño de Una pantera en el sótano, cuando se sorprenda al oír hablar al sargento británico Dunlop y afirme que este suboficial se hablaba en un hebreo "que no es el nuestro" (Oz 2008b: 63), es decir, que el soldado inglés se expresaban en un hebreo aprendido en los textos religiosos. La decisión de los padres de $\mathrm{Oz}$ de educar al niño únicamente en hebreo reproducía la que había tomado Ben Yehuda con su hijo Itamar. Para Ben Yehuda, su primer deseo era implantar el uso del hebreo en la casa, en los espacios íntimos (su programa "El hebreo en el hogar" es buena prueba de ello), por cuanto la casa es el lugar primario de aprendizaje y socialización (Fellman 1973; 1997). Los padres de Oz estaban obsesionados con el hecho de que si su hijo aprendía cualquiera de las lenguas europeas, quedaría fascinado por ese mundo lejano, culto y sofisticado, querría marcharse de Jerusalén y correría el riesgo de ser asesinado (Monmany 2004: 38). Una vez más, Europa como deseo y Europa como peligro. Por su parte, los habitantes de la ciudad seguían utilizando sus lenguas nativas cuando querían crear ambientes de intimidad o cuando querían decirse cosas sin que el resto de las personas conocieran el contenido de sus palabras, o cuando, pese a todo, se hallaban presos de sus recuerdos y desubicados en Eretz Israel. En el caso de las familias de $\mathrm{Oz}$, la lengua "cifrada" era el ruso, en la que hablaban sus padres de temas que no resultaban apropiados para un niño.

Hay, sin embargo, otras dos lenguas mencionadas, pero rechazadas por buena parte de los habitantes cultos de esa Jerusalén de emigrantes judíos: el alemán y el yiddish. El alemán representaba la lengua de los verdugos, por lo que situaciones como la provocada por el sastre berlinés Lazarus anunciando su negocio mitad en hebreo, mitad en alemán, condujo a que alguien arrancara "la parte alemana del cartel, ya que no se admitía entre nosotros el uso del idioma de los asesinos" (Oz 2008b: 29). El yiddish, por su parte, era la koiné de los judíos centroeuropeos. Oz cuenta hasta qué punto su padre lo odiaba por lo que esa lengua y todo lo que se hallaba asociado a ella tenía de mecanismo marcador de diferencias, de elemento referencial del gueto, de los judíos que vivían apartados, de los judíos no cosmopolitas. Hay que tener en cuenta que, pese a vivir 
en un barrio pobre, los padres de Oz disponían de un nivel cultural muy elevado. Su padre fue un gran erudito y un especialista en literatura europea. Su madre había estudiado literatura e historia en la Universidad de Praga. Para ellos, hablar en varios idiomas les permitía compartir varios mundos. El yiddish era la lengua asociada a los judíos más pobres, una lengua proletaria y a la vez, el idioma de los ortodoxos religiosos, para los que el uso del hebreo como lengua común era un sacrilegio.

\section{El otro en la ciudad}

En una entrevista concedida en el año 2006, Amos Oz confesaba al periodista lo siguiente: "Imagino siempre que soy el otro" (Correa Ulloa 2004). Efectivamente, el lector observa en la obra de Oz un intento por indagar en las ideas y en el sentir de ese otro con el que convivimos, tal vez con la sospecha de su personaje Fima:

[...] con la iluminación interior que lo inundaba pensaba a veces que las diferencias entre una persona y otra, entre una persona cualquiera y otra, ya fuera mujer, hombre o niño, no tenían consistencia, excepto tal vez en la capa más externa, en la piel que se muda: al igual que el agua, que adquiere algunas veces forma de nieve, de vaho, de vapor, de hielo, de nubes o de granizo. (Oz 2008d: 27)

Una historia de amor y oscuridad plantea el tema de la alteridad de diversas formas, es decir, no hay una relación unívoca con el otro, pues el otro es plural y el trato con él presenta dificultades variables. Una de las manifestaciones del otro es el árabe. El árabe es un personaje lejano, que no habita en el mundo de Kerem Abraham, que permanece cada vez más separado del judío. El árabe del que se habla en la novela es el árabe racial, pues no se apela a la cuestión religiosa como elemento de separación, es decir, ni árabes cristianos ni árabes musulmanes presentan una identidad claramente definida en la novela. Se hace referencia a ellos como "los árabes". A menudo, el niño Amos se pregunta por ellos, mira los barrios en los que viven, observa, pero no conoce apenas nada de este colectivo. Hay un momento en que acude con sus tíos a una reunión social en casa de una familia árabe enriquecida. Oz ofrece en las escenas que reproducen esta velada las diferencias culturales que separan a ambos pueblos: la manera conveniente de vestir, la forma apropiada de hablar, los temas a los que aludir... Se deja traslucir en su narración la existencia de un gran abismo entre los árabes ricos y ellos, judíos ilustrados de la clase media. En un momento en que el niño Amos está en el jardín intentando comunicarse con dos niños árabes (la cuestión lingüística vuelve a marcar fronteras), tiene lugar un incidente por el cual uno de los niños árabes resulta herido. De 
pronto, la aparente cordialidad que había reinado en la tertulia de los adultos se desvanece y saltan los prejuicios de unos y de otros, sugiriéndose una metáfora de la guerra que estaba a punto de declararse entre ambos, guerra que marcará una frontera interna en el seno de la propia ciudad de Jerusalén: "Un telón de cemento cayó y nos separó de Sheik Jarrah y del resto de los barrios árabes de Jerusalén" (Oz 2008a: 563). Resulta interesante hacer notar, en este sentido, cómo hasta finales de la década de los cuarenta, la literatura israelí mantuvo una actitud bastante utópica con respecto al árabe y, en particular, al árabe de Jerusalén. Autores como Shmuel Yosef Agnón (El enemigo que se volvió amigo) o Yehuda Burla (Amores secretos) confiaban en la posibilidad de construir una convivencia pacífica en el territorio, dado que entendían que ambos, judíos y árabes, tenían en Palestina, y particularmente en Jerusalén, su propio hogar. Hay que recordar que, pese a estallidos de importancia ${ }^{5}$, hasta ese momento, el enemigo era el británico y no el árabe. Sin embargo, desde 1948 la literatura israelí comenzó a acercarse al otro, al árabe, con una visión muy diferente, más combativa (Rajczky 2007). Y será a partir de ahí cuando el otro-árabe se convierta en el otro-enemigo, una mirada de ida y vuelta que conduce al recelo, primero, y al odio, después:

Pero cuando los árabes nos miran, ven ante ellos no a un puñado de supervivientes medio histéricos sino a un nuevo y arrogante emisario de la Europa colonialista, desarrollada y explotadora, que regresa con astucia a Oriente -esta vez con un disfraz sionista- para volver a explotar, despojar y oprimir. Mientras que nosotros, cuando los miramos, vemos ante nosotros no a unas víctimas como nosotros, no a unos hermanos en el sufrimiento, sino a unos cosacos que llevan a cabo pogromos, a unos antisemitas sedientos de sangre, a unos nazis disfrazados: como si nuestros perseguidores europeos hubiesen vuelto a aparecer en Eretz Israel con kefias y bigote, pero fuesen nuestros viejos asesinos cuyo único interés era y sigue siendo cortar las gargantas de los judíos por gusto y diversión. (Oz 2008a: 505)

Otro de los elementos que encarna la alteridad en la novela es el británico. En los años en los que se ambienta el relato, Gran Bretaña ejercía el Mandato de la Sociedad de Naciones sobre Palestina, por lo que el británico es la representación del poder. Como sucedía con el árabe, el británico tampoco alcanza un protagonismo importante en el transcurrir de la vida del niño Amos. Aparece como uno de esos personajes sofisticados que vive "en el mundo verdadero", es decir, lejos y al margen de los barrios judíos pobres.

\footnotetext{
${ }^{5}$ En 1936 estalló una sublevación árabe de gran magnitud impulsada por el muftí de Jerusalén, Muhammad Amin Al-Huseini, que tenía como objetivo la expulsión de los judíos que llegaban a Palestina huyendo del nazismo.
} 
Oz tratará más a fondo la relación con el británico y lo que éste significa en la ciudad de Jerusalén en otra de sus novelas: Una pantera en el sótano, y en relatos como los contenidos en The Hill of Evil Counsel, no traducidos al español. El británico es analizado en una doble dimensión: como grupo e individualmente. Amos $\mathrm{Oz}$ ha confesado en varias ocasiones la pésima opinión que le merece la actuación de los británicos en Jerusalén durante la época del Mandato y que reproduce en parte en las palabras del padre de Profi:

El hecho de dominar nuestro país se basa en la explotación y la mentira, ya que los países del mundo les encargaron Jerusalén con el compromiso de promover aquí la construcción de un hogar para el pueblo de Israel y ahora instigan a los árabes a que arrasen ese hogar, incluso los ayudan. (Oz 2008b: 125)

En declaraciones a la prensa, Amos $\mathrm{Oz}$ se ha manifestado en la misma línea. Estas son las palabras con las que contestaba a la periodista y novelista Rosa Montero:

Realmente una buena parte de la tragedia en Oriente Próximo ha sido causada por la hipocresía y los engaños de los británicos, porque esencialmente hicieron un juego doble de engaño con judíos y con árabes. Prometieron la misma tierra a las dos partes, prometieron dos veces la misma tierra, y después, naturalmente, intentaron fomentar el enfrentamiento entre árabes y judíos para permanecer en el poder y seguir controlando la zona. (Montero 2007)

Por el contrario, cuando se ocupa del individuo concreto, cuando fija su atención en el sargento Dunlop, Oz ve a una persona, con todo lo que esto significa, a una persona que quiere conocer al judío por medio del estudio de su idioma.

Sin embargo, el otro por antonomasia en Una historia de amor y oscuridad es la sombra del judío muerto, del judío asesinado en los campos de concentración o en las localidades de las que proceden los personajes de la novela. El judío muerto no vive físicamente en la ciudad, pero sí en el alma de sus refugiados, hasta el punto de que buena parte de esa opresión que el niño Amos siente viene del recuerdo, de la memoria. La Jerusalén del emigrado judío es una ciudad impregnada de recuerdos, sumergida en la melancolía de un mundo que se dejó atrás, en un mundo imposible a todas luces. De este modo, Jerusalén se convierte en un lugar para la memoria grabada en la roca. Sin apenas mencionarlo y a través de estas sugestiones, Amos Oz plantea la cuestión de cómo integrar el Holocausto en la memoria de los judíos que habitan tanto en Jerusalén como en Israel. Hasta tal punto queda grabado en las mentes de los personajes que pueblan Una historia de amor y oscuridad que podría decirse, como se ha señalado en análisis 
sociológicos de otro tipo, que el simbolismo del Holocausto ha llegado a constituir un elemento identitario del judío israelí (Sznajder 2007: 39). En este sentido, el Holocausto es el catalizador de todos los miedos que pesan sobre la población, de esos miedos agobiantes que generarán el deseo del niño Amos $\mathrm{Oz}$ de construirse una nueva identidad judía fuerte, segura, lejos de Jerusalén, de la ciudad del recuerdo.

En esa presencia del judío desaparecido en la ciudad y en las casas de sus habitantes juegan un papel fundamental las fotografías que traen a la memoria los tiempos en los que los ahora refugiados habitaban en las añoradas ciudades europeas (que ya son ciudades imposibles); los tiempos en los que los muertos aún vivían. En el caso de la familia Klausner, el tío del niño Amos, David; su esposa, Malka, y su hijo Daniel. Las fotografías familiares son reiteradamente observadas por el protagonista para entender no su pasado, que es plenamente hebreo israelí, sino el de tantos refugiados en Jerusalén que habitan emocionalmente en otro espacio y en otro tiempo. La sensación de desarraigo de tantos de ellos cree poderla explicar el autor a través del propio caso de su tío David: una imposibilidad de entender que el mundo caminaba por otros lugares que no eran los del cosmopolitismo intelectual, y la ficción de su propio sionismo, que le condujo a preferir permanecer en Europa, en lugar de marchar a Jerusalén, un lugar "demasiado asiático". Con estas palabras nos describe Oz el sentimiento de su tío David:

El tío David era un eurófilo convencido, especialista en literatura comparada, en literaturas europeas que eran su patria espiritual. No entendía por qué tenía que renunciar a su puesto y emigrar al Asia oriental, un lugar desconocido y extraño para él, sólo para cumplir los deseos de unos antisemitas ignorantes y de unos bandidos nacionalistas sin cerebro. Por tanto, se quedó en su cargo, con el fin de servir al progreso de la cultura hasta que los nazis llegaron a Vilna. (Oz 2008a: 105-106)

Frente al judío muerto y su sombra, aparece en la obra de $\mathrm{Oz}$ otra encarnación del judío: el nuevo hombre hebreo. El hombre fuerte, seguro de su identidad judía, el sueño de los padres de Oz y de tantos otros por criar en Israel al nuevo judío sin complejos, el habitante del nuevo estado, en la dinámica sionista de la destrucción (el Holocausto) y el renacimiento (la creación del estado) (Ofer 2000: 38-42):

Nuestros padres esperaban que nosotros, los niños, creciéramos y nos convirtiéramos en judíos totalmente nuevos, mejores, de hombros anchos, guerreros y agricultores [...] para que llegado el momento, pudiéramos resistir, curtidos y firmes, y esta vez no permitiéramos que el enemigo nos llevase como ovejas al matadero. (Oz 2008b: 36) 
Sin embargo, el nuevo hombre hebreo no habita en Jerusalén, sino en el "resto del mundo", en los kibbutzim, en Tel Aviv, en Haifa: "[...] la Jerusalén judía no era joven y no estaba armada ni erizada sino que era un pueblo chejoviano: asustada, despistada, saturada de cotilleos y falsos rumores, ofuscada, aturdida por la confusión y el miedo" (Oz 2008a: 509).

\section{La ciudad fragmentada}

El 29 de noviembre de 1947 se votó y firmó la partición de Palestina y finalizó, por tanto, el Mandato británico en el territorio. Poco después, el 14 de mayo de 1948, se crearía el estado de Israel. En esos meses dio comienzo la que es llamada primera guerra árabeisraelí. Una historia de amor y oscuridad es, como ya se ha dicho, una novela del Jerusalén judío, por tanto Amos $\mathrm{Oz}$ nos cuenta estos acontecimientos desde el lado hebreo, la percepción judía de lo que supuso el inicio del estado. Hay una imagen repetida tantas veces que al lector le resulta difícil discernir si lo que guarda en su imaginario es producto de sus lecturas (Oh, Jerusalén) o de escenas vistas en películas (Éxodo) o en los medios de comunicación. Se trata de la votación de la partición y de cómo se vivió en las calles de Jerusalén tan trascendental acontecimiento. Amos $\mathrm{Oz}$ también describe aquella noche en que las gentes ocuparon el espacio público, salieron de sus opresivos alojamientos para oír la radio con el resto de sus vecinos, para respirar, tanto en un sentido físico como metafórico, lo que para ellos suponía la libertad, al fin, como pueblo. De este modo, la ciudad asfixiante se convierte por unas horas en la ciudad festiva, tras una fugaz aparición del "judío muerto", en quien parecen todos pensar antes de lanzarse a las celebraciones:

[...] también nuestra calle perdida a un extremo de Kerem Abraham, al norte de Jerusalén, rugió de pronto con un primer y terrible grito que desgarró la oscuridad, los edificios y los árboles, y se fragmentó, un grito no de alegría, no se parecía en nada al clamor de la multitud en los estadios deportivos, no se parecía al desenfreno de una muchedumbre exaltada, tal vez era más como un alarido de terror y pavor, que helaba la sangre, como si todos los muertos del pasado y del futuro hubieran podido por un instante gritar a través de un diminuto ventanuco cerrado de inmediato, y un momento después, el primer grito de terror dejó paso a clamores de alegría y a una mezcla de bramidos roncos y iel pueblo de Israel vive! [...] y toda la multitud comenzó a moverse lentamente alrededor de sí misma como llevada por un gigantesco remolino y ya nada estaba prohibido. (Oz 2008a: 523)

En este momento, Jerusalén parece fundirse con el nuevo estado, convertirse en un símbolo. El mito político se hermana con el 
mito religioso y la ciudad es la gran roca a la que deben asirse todos los judíos del mundo.

Sin embargo, y como en una especie de maldición divina, la ciudad se siente castigada en su efusión de alegría y libertad y ha de expiar sus excesos en una nueva guerra, esta vez contra los árabes, contra ese otro al que no se ha intentado comprender al tratar de comprenderse los judíos a sí mismos, al tratar de entender su desgracia como pueblo. En la guerra, Oz nos presenta también la ciudad asediada: la dureza de la vida cotidiana, los obuses lanzados sobre las casas, las restricciones, las cartillas de racionamiento. La ciudad épica, de la lucha contra el británico, se convierte en la ciudad gris, la de las necesidades cotidianas. De nuevo, con la llegada de los judíos que vivían en los países árabes, Jerusalén vuelve a ser una ciudad agobiante, Ilena. La propia casa de la familia Oz se convierte en un espacio más angustioso, ya que sirve de refugio a los vecinos y familiares en las noches de bombardeo. Comienza una transformación, la ciudad se expande para dar cabida a los recién llegados, crece de manera informe, creando nuevos barrios tristes y grises como Kerem Abraham. Y mientras tanto, al poco tiempo de estallar la guerra, el núcleo espiritual, la parte judía de la Ciudad Vieja, ha caído en manos de los árabes. El mito político ha perdido su recientemente conquistado mito religioso. De este modo, el otro, el extraño, el árabe, adquiere identidad y se convierte en el enemigo. Sus golpes son recibidos con golpes: la ciudad sólo puede ser para una de las dos partes. El miedo al otro modifica la propia percepción de la ciudad, cuyas fronteras judías se desdibujan cada día en función de la evolución de la guerra. La ciudad se fragmenta, los antiguos itinerarios han de ser variados para no traspasar el territorio que ahora pertenece al otro. De forma simbólica, como confiesa el niño Amos: "los meses de bombardeos, hambre y miedo habían endurecido mi corazón" (Oz 2008a: 541). Estos momentos tan duros en la Jerusalén en guerra representan también la maduración del propio niño. Oz lo recuerda con estas palabras: "Esa noche, por primera vez, comprendí que también yo moriría" (Oz 2008a: 548).

\section{Conclusión}

Jerusalén es la ciudad de la piedra, la roca dura de la memoria atrapada en el mineral, fijada en un territorio ardiente, reseco. Para analizar la ciudad de Jerusalén hay que tener siempre en cuenta la realidad material y física, pero también su realidad simbólica (Bulle 2006: 588). Y en esta realidad simbólica, la memoria es fundamental. El tema de la memoria está siempre presente en las narraciones sobre Jerusalén $y$, como tal, se ha querido reflejar en este trabajo a través de la obra de Oz. El poeta Yehuda Amichai, tal vez pensando en el viejo salmo ("Si me olvidare de ti, oh Jerusalén...") escribió unos significativos versos sobre ella en relación a esta cuestión: 
"Jerusalén, lugar donde todos recuerdan / que se les ha olvidado algo, / sin recordar qué era". Amos $\mathrm{Oz}$, en su principal obra, aquí comentada, como en otras tantas, ha tratado de conjurar sus propios demonios a través de ella, liberándose de su pasado al escribir sobre la ciudad de su infancia. Aun así, como dice su personaje Jana, la ciudad sigue siendo un secreto inescrutable que cada uno debe intentar descubrir:

En cada barrio, en cada suburbio, hay una realidad oculta por una alta muralla. Fortalezas hostiles cerradas a los viandantes. Me pregunto si alguien podría integrarse en Jerusalén aunque viviera en ella cien años. Es una ciudad de patios cerrados, su alma está sellada tras muros sombríos con afilados cristales clavados en lo alto. Jerusalén no existe. Migas arrojadas a propósito para confundir a los ingenios. Una piel debajo de otra y el hueso preso dentro. (Oz 2007: 107-108)

\section{Bibliografía}

BALABAN, Abraham (1993): Between God and Beast: an examination of Amos Oz's prose. Pennsylvania: Pennsylvania University Press.

BEN DOV, Nitza (2009): The Amos Oz Reader. Boston: Houghton Mifflin Harcourt.

BERRIOT-SALVADORE, Évelyne (ed.) (1995): Le Mythe de Jérusalem du Moyen Âge à la Renaissance. Saint-Étienne: Publications de I'Université de Saint-Étienne.

BULLE, Sylvaine (2006): "Espace et mémoire collective à Jérusalem". Annales, num. 3, pp. 583-608.

CLAPARĖDE-ALBERNHE, Brigittte (2005): Amos Oz, une écriture de paix. Paris: L'Harmattan.

CORREA ULLOA, Juan David (2004): "Entrevista a Amos Oz" [en línea]. Arcadia, núm. $11 . \quad$ En: http://www.revistaarcadia.com/libros/articulo/imagino-siempreotro/20327 [Consulta: marzo de 2011].

FELLMAN, Jack (1973): The revival of a classical tongue. Eliezer Ben Yehuda and the Modern Hebrew Language. Paris: Mouton.

- (1997): "Eliézer Ben Yehuda y el renacimiento de una lengua" [en línea]. Ariel. Revista de Artes y Letras de Israel, núm. 104. En: http://www.mfa.gov.il/mfaes/mfaarchive [Consulta: marzo de 2011].

GUR, Batya (2000): Jérusalem, une leçon d'humilité. Paris: Gallimard.

HALBWACHS, Maurice (1941): La topographie légendaire des Évangiles en Terre Sainte. Étude de mémoire collective. Paris: Alcan.

MAZOR, Fair (2002): Somber Lust: the art of Amos Oz. Albany: State University of New York Press.

MONMANY, Mercedes (2004): "Entrevista con Amoz Oz. Europa y los judíos: historia de un amor traicionado". Letras Libres, diciembre, pp. 36-39.

MONTERO, Rosa (2007): "Entrevista a Amos Oz". El País Semanal, 28/10/2007. 
OFER, Dalia (2000): "The Strength of Remembrance: Commemorating the Holocaust during the First Decade of Israel". Jewish Social Studies, vol. 6, núm. 2, pp. 2-55.

OZ, Amos (1978, 1976): The Hill of Evil Counsel. Londres: Chatto and Windus.

- (1993, 1966): Quizás en otra parte. Buenos Aires: Emecé Editores.

- (2007, 1968): Mi querido Mijael. Madrid: Siruela.

- (2008a, 2002): Una historia de amor y oscuridad. Madrid: Siruela.

- (2008b, 1994): Una pantera en el sótano. Madrid: Siruela.

- (2008c, 1978): La bicicleta de Sumji. Madrid: Siruela.

- (2008d, 1991): Fima. Madrid: Siruela

- (2009, 1971): Hasta la muerte. Madrid: Siruela.

RACJZKY, Tamara (2007): "Literatura y conflicto" [en línea]. Revista horizonte, julio de 2007. En: http://www.revistahorizonte.org/ [Consulta: marzo de 2011].

- (s/f): Literatura israelí en español [en línea]. En: http://www.literaturaisraeli.com.ar/ [Consulta: marzo de 2011].

SANGUIN, André-Louis (1995): "La dimension politique des lieux sacrés: la vieille ville de Jérusalem entre la Bible et le Coran". Bulletin de I'Association de géographes français, vol. 82, num. 1, pp. 48-62.

SZNAJDER, Mario (2007): "Del Estado-refugio al Estado-conflicto: el Holocausto y la formación del imaginario colectivo israelí". Revista Mexicana de Ciencias Políticas y Sociales, núm. 200, pp. 25-48.

VARELA MORENO, Ma Encarnación (1992): Historia de la literatura hebrea contemporánea. Barcelona: Mirador. 